\title{
Inhibition of NF-kB activation and chemokine expression by the leukocyte glycoprotein, CD43, in colon cancer cells
}

\author{
SIRLE LAOS, DAN BAECKSTRÖM and GUNNAR C. HANSSON
}

\author{
Department of Medical Biochemistry, Göteborg University, Medicinaregatan 9A, 41390 Gothenburg, Sweden
}

Received September 16, 2005; Accepted November 4, 2005

\begin{abstract}
CD43 is a heavily $O$-glycosylated type I transmembrane protein, expressed at high levels on the surface of leukocytes. It is frequently overexpressed in early colon adenomas, but not in normal colon epithelial cells. To identify CD43 target genes, gene array analysis was performed using a tetracycline-inducible CD43 expression system in human colon adenocarcinoma SW480 cells. CD43 was demonstrated to down-regulate a variety of chemokine genes. Overexpression of CD43 suppressed constitutive as well as PMA-induced $\mathrm{NF}-\kappa \mathrm{B}$ activation and reduced the DNA binding of transcription factor p65 but not p50. Furthermore, a reduced $\mathrm{NF}-\kappa \mathrm{B}$ responsive promoter activity was observed and a decreased expression of proinflammatory chemokines MCP-1, IL- 8 and GRO- $\alpha$. These results suggest that overexpression of CD43 suppresses a subset of NF- $\mathrm{KB}$ target genes, partly via the inhibition of $\mathrm{p} 65$ transcriptional activity.
\end{abstract}

\section{Introduction}

Cancer cells are known to express aberrant cell surface glycoproteins, such as MUC1 and CD44, suggested to have a role during cancer development by altering tumor cell adhesion, signaling and affecting immune surveillance. Another such molecule is CD43 (leukosialin, sialophorin), which under normal conditions is expressed on the surface of almost all hematopoietic cells (1). First, high CD43 expression was found in the colon cancer cell line, COLO205, and later at various levels in other intestinal cancer cell lines, such as Caco-2, HT-29, DLD-1 and SW480 (2). Moreover, CD43 expression was observed in a range of human tumors of epithelial origin (3). In particular, aberrant CD43 expression was found in early stages of human colorectal tumors but not in the normal colon epithelium $(4,5)$, suggesting a role in colon tumor development.

CD43 is a type I transmembrane molecule. It has a mucinlike highly $O$-glycosylated extracellular domain with an

Correspondence to: Dr Gunnar C. Hansson, Department of Medical Biochemistry, Göteborg University, Box 440, 40530 Göteborg, Sweden

E-mail: gunnar.hansson@medkem.gu.se

Key words: leukosialin, sialophorin, colon adenoma, NF-кB, p65 extended structure (6). The intracellular part of CD43 is evolutionarily conserved and has no intrinsic catalytic activity but contains a number of potential protein kinase $\mathrm{C}$ (PKC) phosphorylation sites and an SH3-binding consensus sequence $(6,7)$, suggesting that the intracellular domain of CD43 is involved in signal transduction. In hematopoietic cells, CD43 is ubiquitously expressed, but its multiple and complex functions remain controversial. However, CD43 has been demonstrated to be involved in regulation of cell adhesion (both pro- and anti-adhesion), immune responses, proliferation, survival and apoptosis.

The CD43 glycoprotein plays an important role in immune regulation. Differences in $\mathrm{O}$-glycosylation give rise to different CD43 isoforms affecting the development, survival and reactivity of blood cells. For example, resting $\mathrm{T}$ lymphocytes express predominantly a $115-\mathrm{kDa}$ isoform of CD43; however, upon activation more complex carbohydrate structures appear on CD43 resulting in a $130-\mathrm{kDa}$ form (8). In T cell activation, both positive and negative regulatory roles have been ascribed to CD43. Several reports suggest that CD43 serves as a costimulatory receptor for $\mathrm{T}$ cell activation and show that the intracellular part of CD43 is involved in the formation of signal transduction complexes $(9,10)$. On the contrary, T cells from CD43-deficient mice showed enhanced cytotoxic $\mathrm{T}$ cell responses and a delay in the down-modulation of immune responses, suggesting a negative regulatory role for CD43 $(11,12)$. Besides, CD43 is actively excluded from immunological synapse by the ezrin-radixin-moesin (ERM) family of proteins allowing $\mathrm{T}$ cell activation (13). CD43 has been implicated to play a positive role in $\mathrm{T}$ cell homing to secondary lymphoid organs and peripheral tissue (14). Alterations in CD43 glycosylation in $\mathrm{T}$ cells have been linked to two unrelated human immunodeficiency diseases, Wiskott-Aldrich syndrome (WAS) (15) and acquired immune deficiency syndrome (AIDS) (16).

In tumor cells, CD43 has been speculated to interfere with immune cell interactions by making them more inefficient (17) and protect cells from Fas-induced cell death (18). However, CD43 probably has an even more diverse function and it can directly affect tumor cell signaling as indicated by its interaction with the oncogene $\beta$-catenin (19). Moreover, CD43 overexpression, as a potential oncogenic stimulus, caused activation of the tumor suppressor proteins, p53 and ARF (20).

As CD43 expression has been found in colon adenomas, we have now asked how CD43 overexpression affects colon cancer cells to reveal how CD43 contributes to adenoma and maybe tumor development. We provide evidence that CD43 
overexpression inhibits NF- $\mathrm{KB}$ transcriptional activity and reduces DNA binding of the transcription factor, p65. Thereby, it may suppress the expression of genes involved in the regulation of immune responses.

\section{Materials and methods}

Cell culture. The human colon adenocarcinoma cell line, SW480, and the mammary gland adenocarcinoma cell line, MCF7, were cultivated in Iscove's medium containing $10 \%$ fetal bovine serum (Gibco-BRL) or 10\% Tetracycline System Approved FBS (BD), and 1\% penicillin-streptomycin (Invitrogen). To generate SW480/TR and MCF7/TR cell lines the pcDNA6/ TR regulatory plasmid of the tetracyclineinducible (tet-on) expression system, T-REx (Invitrogen), was transfected and selected by $10 \mu \mathrm{g} / \mathrm{ml}$ Blasticidin. Human full-length CD43 cDNA was cloned into the pcDNA4/TO expression plasmid, transfected into cells with the TR regulatory plasmid and stable clones selected by $50 \mu \mathrm{g} / \mathrm{ml}$ Zeocin. Protein overexpression was induced by $0.5-0.75 \mu \mathrm{g} / \mathrm{ml}$ tetracycline.

Gene chip microarray. Total RNA was extracted from $38 \mathrm{~h}$ tet-on and non-induced SW480/CD43 cells using an RNeasy mini kit (Qiagen), converted to cDNA, and hybridized to human U133 A/B chips (Affymetrix) by SweGene Microarray Centre (Lund, Sweden).

$R T$-PCR. For RT-PCR experiments, the cells were induced for indicated times and the total RNA extracted using the RNeasy mini kit (Qiagen). For RT-PCR the ProSTAR ${ }^{\circledR}$ HF Single-Tube RT-PCR system (Stratagene) was used with a final volume of $50 \mu 1$, containing $200 \mathrm{ng}$ RNA and 10 pmol each primer. The primers used were: GRO- $\alpha$ (forward 5'-CA CCCCAAGAACATCCAAAG-3'; reverse 5'-TGCTCAAAC ACATTAGGCACA-3'), IL-8 (forward 5'-TCTCAGCCCTC TTCAAAAACTTCT-3'; reverse 5'-ATGAACTTCCAAGCT GGCCGTGCT-3'), and MCP-1 (forward 5'-CACTCACTCC ACAACCCAAG-3'; reverse 5'-GCAAAGACCCTCAAAAC ATC-3'). The primers for $B$-actin were obtained from Applied Biosystems. For the PCR, 2.5 U Taq DNA polymerase (Invitrogen) was used and the reaction was conducted using GenAmpPCR system 9600 (Perkin-Elmer) at $42^{\circ} \mathrm{C}$ for $30 \mathrm{~min}$, followed by $95^{\circ} \mathrm{C}$ for $1 \mathrm{~min}$. The RT product was amplified by 20,25 and 30 cycles of $95^{\circ} \mathrm{C}(30 \mathrm{sec}), 60^{\circ} \mathrm{C}(30 \mathrm{sec})$ and $68^{\circ} \mathrm{C}$ ( $2 \mathrm{~min}$ ). The amplified fragments were resolved by $2 \%$ agarose gel electrophoresis and visualized with ethidium bromide.

Antibodies, Western blot analysis and immunocytochemistry. Two mAbs against human CD43 were used; $\alpha$ CD43-L10 reacting with the extracellular domain (21) and $\alpha \mathrm{CD} 43-4 \mathrm{D} 2$ with the intracellular domain of CD43 (22). The monoclonal antibodies for $\mathrm{p} 65$ and $\mathrm{I} \kappa \mathrm{B} \alpha$ were from BD, and PPAR- $\gamma$ and rabbit polyclonal anti- $\beta$-catenin were from Santa Cruz Biotechnology. The polyclonal p50 antibody was from Upstate Biotechnology and B-actin AC-15 antibody was from Sigma.

Cytoplasmic and nuclear extracts were prepared using NE-PER ${ }^{\text {TM }}$ nuclear and cytoplasmic extraction kit (Pierce) according to the manufacturer's protocol, except for 3 additional washing steps with $0.1 \%$ NP-40 in PBS before nuclear lysis.
Complete EDTA-free protease inhibitor mixture (Roche) was added to the lysis buffers. Equal amounts of extracts, as determined by the BCA protein assay (Pierce), were analyzed by $10 \%$ homogenous SDS-polyacrylamide gel, transferred electrophoretically onto Immobilon P (Millipore), blocked with PBS- $0.1 \%$ Tween-20 containing 5\% milk powder, and probed with primary antibody diluted in block solution. Secondary antibodies (alkaline phosphatase or horseradish peroxidase conjugated, Dako) were diluted 1:2000 and developed with BCIP/NBT (Sigma) or SuperSignal West Pico (Pierce).

For p65 shuttling experiments, the cells were treated for $24 \mathrm{~h}$ with $10 \mathrm{ng} / \mathrm{ml}$ leptomycin B (Sigma). Alexa Fluor 488 anti-mouse IgG (Molecular Probes) was used as a secondary antibody for light microscopy.

Flow cytometry. Approximately $10^{6}$ cells were washed with PBS and resuspended in FACS solution (1\% BSA in PBS). For intracellular staining, the cells were kept on ice for $30 \mathrm{~min}$ with $0.05 \%$ saponin containing FACS solution. Primary antibody $(2 \mu \mathrm{g} / \mathrm{ml})$ was added to the cells and incubated on ice for 1-2 h. The cells were washed twice with FACS solution followed by centrifugation at $200 \mathrm{x} g$ for $5 \mathrm{~min}$. The cells were incubated with 1:100 diluted fluorescein-conjugated antimouse antibody (Dako) in FACS solution on ice for 45 min and washed as above. The samples were analyzed using a FACScalibur $^{\mathrm{TM}}$ cell sorter (BD).

Chemokine ELISA. Spent cell culture media were collected and the level of IL-8, MCP-1 and GRO- $\alpha$ measured using colorimetric ELISA kits (R\&D). The concentrations are given in $\mathrm{pg} / \mathrm{ml}$ of the collected cell culture media.

Transfections and luciferase reporter assays. The cells were transiently transfected with DMRIE-C (Invitrogen) or Fugene6 (Roche) according to the manufacturer's protocol. The NF-кBluc reporter plasmid was a kind gift from Dr Ian Whitehead. The pAP-1-luc plasmid was obtained from PathDetect AP-1 cis-Reporting System (Stratagene). The B-catenin reporter system, pTOPFash, was used as described by (19). For the transfections, $1.5 \times 10^{5}$ cells were seeded in triplicates to 12 well plates $24 \mathrm{~h}$ before transfection. For transfection, $1 \mu \mathrm{g}$ of AP-1-luc and NF-кB-luc reporter plasmids were used. The cells were treated for $24 \mathrm{~h}$ with $100 \mathrm{ng} / \mathrm{ml}$ PMA (Sigma). The cells were harvested $24 \mathrm{~h}$ after transfection with Passive Lysis buffer, and the luciferase activity determined (Promega Luciferase Assay). Relative light units (RLU) were measured using a Lumat 9501 luminometer (Berthold). All transfections were normalized to the level of total cellular protein by the BCA protein assay (Pierce). The results were analyzed by two-tailed unpaired t-test using the SPSS statistical package, and the level of significance was taken as $\mathrm{p}<0.05$.

$N F-\kappa B$ DNA binding activity. Nuclear extracts were obtained using a $\mathrm{BD}^{\mathrm{TM}}$ TransFactor extraction kit. The NF-кB DNA binding activities in nuclear extracts $(35 \mu \mathrm{g})$ were quantified employing a Mercury ${ }^{\mathrm{TM}}$ TransFactor NF-кB family and p65 kit (BD).

RNAi. For p65 RNAi, 7x105 cells were transfected with $0.5 \mu \mathrm{g}$ siRNA (SMARTpool NF-кB p65/RelA, Upstate Biotech- 
nology) using the RNAi human/mouse control kit reagents (Qiagen). As a control, Alexa Fluor 488-labeled non-silencing siRNA was used. At $70 \mathrm{~h}$ after transfection, cells and medium were harvested and processed for Western blotting and MCP-1 ELISA.

\section{Results}

Overexpression of CD43. As a model to study the effect of observed CD43 expression in colon adenomas (4), a CD43 or lacZ tetracycline-inducible system was established in the colorectal adenocarcinoma cell line, SW480. Since CD43 expression was also found in breast carcinomas (3), the same system was also set up in the mammary gland adenocarcinoma cell line, MCF7. The different cells are referred to as SW480/ CD43, MCF7/CD43, SW480/lacZ and MCF7/lacZ, whereas MCF7/TR cells only express the tetracycline repressor protein. Both studied cell lines, however, express low levels of endogenous CD43 (2). To verify CD43 overexpression after $48 \mathrm{~h}$ of tetracycline induction (48-h tet-on), the cells were studied by FACS using mAb $\alpha C D 43-4 D 2$ against the cytoplasmic tail of human CD43 (Fig. 1A). An approximate 4-fold increase in the expression of CD43 was observed in SW480/CD43 cells, whereas tetracycline induction of MCF7/CD43 cells caused higher expression levels of CD43 compared to SW480 cells. The level of CD43 expression achieved after induction in SW480/CD43 cells is comparable with the endogenous CD43 expression levels in the human leukemic cell line, K562, and the colorectal adenocarcinoma cell line, COLO205 (2). SW480/ CD43 cells were further analyzed by Western blotting using $\mathrm{mAb} \alpha \mathrm{CD} 43-4 \mathrm{D} 2$ (Fig. 1B). The observed masses of CD43 are similar to those described previously (23). After 24-h tet-on, the precursor band of CD43 was found at approximately $54 \mathrm{kD}$, and the glycosylated mature forms as a smear between 110 and $150 \mathrm{kD}$, which further increased in amounts after $48-\mathrm{h}$ tet-on. To verify the cell membrane localization of overexpressed CD43, non-permeablised cells were stained with $\mathrm{mAb} \alpha \mathrm{CD} 43-\mathrm{L} 10$, reacting with an extracellular epitope on CD43. An approximate 3.5-fold increase in CD43 surface expression was observed in the SW480/CD43 cells by FACS (Fig. 1C). The localization of CD43 to the cell membrane was almost exclusive as shown by immunohistochemistry using $\mathrm{mAb} \alpha \mathrm{CD} 43-4 \mathrm{D} 2$ in the permeablilized clone of SW480/CD43 (Fig. 1E). This localization was previously also shown by confocal microscopy (2). It should be emphasized that the expression level of CD43 in the non-induced SW480/CD43 cells was higher than in the SW480/lacZ cells, due to the general problem of this system with incomplete repression of this inducible promoter (Fig. 1D).

CD43 alters the gene expression in cancer cells. To identify genes whose mRNA expression level had changed upon CD43 overexpression, the cDNA from non-induced and $38 \mathrm{~h}$ tet-on SW480/CD43 cells were analyzed on the human Affymetrix gene array. Using a $>3$-fold difference as criterion of differential expression, 18 genes were identified (Table I). Only four genes were up-regulated upon CD43 overexpression including an apoptosis-related serine/threonine kinase $17 \mathrm{a}$ (DRAK1). The identities of the others are unknown and have not been studied further. Instead, most of the affected genes
A

\section{Controls}
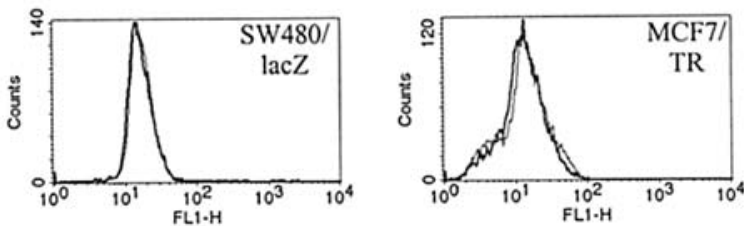

CD43 clones
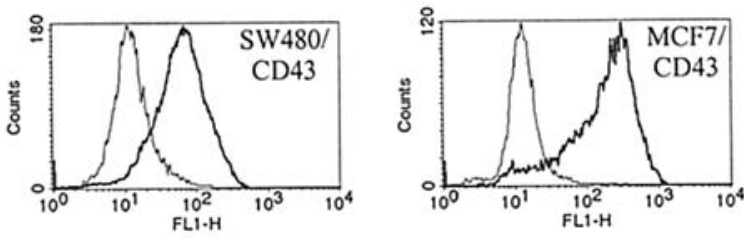

CD43 pool of clones

C
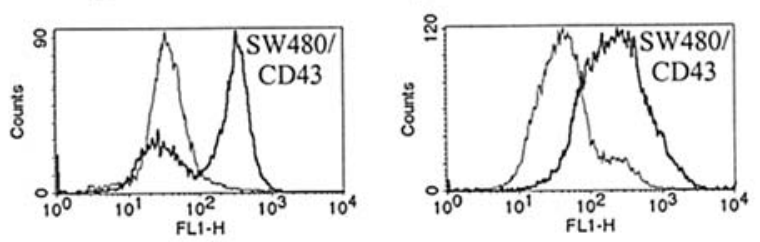

B

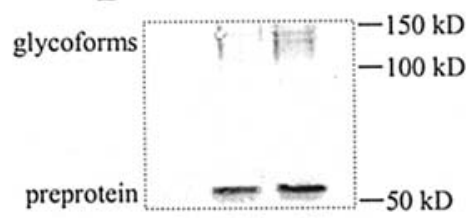

Tet $0 \mathrm{~h} \quad 24 \mathrm{~h} \quad 48 \mathrm{~h}$

D

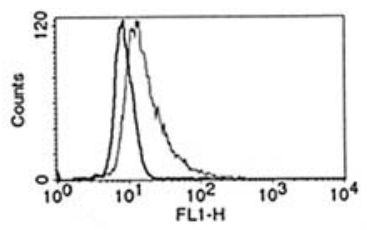

$\mathbf{E}$
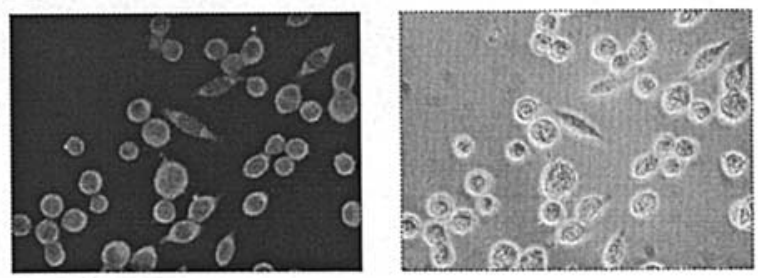

Figure 1. Tet-on overexpression of CD43 and lacZ in the colon adenocarcinoma cell line, SW480, and the mammary gland adenocarcinoma cell line, MCF7. (A) FACS analysis of intracellular CD43. Permeabilized cells were stained with mAb $\alpha \mathrm{CD} 43-4 \mathrm{D} 2$ against the cytoplasmic domain of CD43, followed by FITC-conjugated secondary anti-mouse antibody. Thin line, non-induced cells; bold line, 48-h tet-on cells. (B) Western analysis of 24-, 48-h tet-on SW480/CD43 cells using mAb $\alpha$ CD43-4D2. The preprotein of CD43 migrated as a 54-kD band, and glycosylated mature forms as a smear between 110 and $150 \mathrm{kD}$. (C) FACS analysis of the cell surface expression of CD43 in non-permeablised 48-h tet-on SW480/CD43 cells, using mAb $\alpha \mathrm{CD} 43-\mathrm{L} 10$ reacting with the extracellular domain of CD43, followed by FITC-conjugated anti-mouse antibody. (D) Comparison of CD43 expression between SW480/lacZ (bold line) and non-induced SW480/ CD43 (thin line) cells. The cells were cultivated using 10\% Tetracycline System Approved FBS and stained with mAb $\alpha$ CD43-4D2 followed by FITC-conjugated anti-mouse antibody. (E) Localization of CD43 in 48-h tet-on SW480/CD43 cells as studied by light fluorescence microscopy. The cells were stained with mAb $\alpha \mathrm{CD} 43-4 \mathrm{D} 2$, followed by Alexa488-conjugated secondary anti-mouse antibody.

showed decreased expression, including several chemokines belonging to the CXC and CC families. The MCP-1 (CCL2) expression decreased 4-fold and the other chemokines, such 
Table I. Gene expression alterations upon overexpression of CD43 according to Affymetrix gene chip U133

\begin{tabular}{|c|c|c|c|}
\hline Affymetrix ID & GenBank ID & Description & Fold change \\
\hline \multicolumn{4}{|l|}{ Down-regulated } \\
\hline 215069_at & AK025065 & N-myristoyltransferase 2 (NMT2) & $6.4 \downarrow$ \\
\hline 242518_at & AA748423 & Hypothetical protein LOC90408 & $5.8 \downarrow$ \\
\hline 209328_x_a & ВC000587 & Hypothetical protein HSPC111 & $4.4 \downarrow$ \\
\hline 233703_x_at & AK024236 & cDNA FLJ14174 fis, clone NT2RP2002843 & $4.4 \downarrow$ \\
\hline 216598_s_at & S69738 & Chemokine (C-C motif) ligand 2 (CCL2, MCP-1) & $4.0 \downarrow$ \\
\hline 222180_at & AU147889 & cDNA clone FLJ14122 fis, clone MAMMA1002033 & $3.8 \downarrow$ \\
\hline 227509_x_at & W18193 & cDNA FLJ40982 fis, clone UTERU2014601 & $3.8 \downarrow$ \\
\hline 210748_at & AF116696 & DnaJ (Hsp40) homolog, subfamily C, member 8 & $3.8 \downarrow$ \\
\hline 207798_s_at & NM_017492 & Ataxin 2 related protein (A2LP) & $3.4 \downarrow$ \\
\hline 231819_at & BG505096 & cDNA clone IMAGE:5261836, partial cds & $3.4 \downarrow$ \\
\hline 202859_x_at & NM_000584 & Interleukin 8 (IL-8) & $3.0 \downarrow$ \\
\hline 204470_at & NM_001511 & Chemokine (C-X-C motif) ligand 1 (CXCL1, GRO- $\alpha$ ) & $3.0 \downarrow$ \\
\hline 210941_at & $\mathrm{AB} 006756$ & Protocadherin 7 (PCDH7. BH-Pcdh) & $3.0 \downarrow$ \\
\hline 242260_at & BG283790 & Matrin 3 (MATR3) & $3.0 \downarrow$ \\
\hline 207850_at & NM_002090 & Chemokine (C-X-C motif) ligand 3 (CXCL3, GRO- $\gamma$ ) & $2.4 \downarrow$ \\
\hline 207339_s_at & NM_002341 & Lymphotoxin ß (LTß) & $2.4 \downarrow$ \\
\hline 210317_s_at & U28936 & Epsilon 14-3-3 & $2.4 \downarrow$ \\
\hline 209774_x_at & NM_002089 & Chemokine (C-X-C motif) ligand 2 (CXCL2, GRO- $\beta$ ) & $2.2 \downarrow$ \\
\hline 208075_s_at & NM_006273 & Chemokine (C-C motif) ligand 7 (CCL7, MCP-3) & $2.2 \downarrow$ \\
\hline \multicolumn{4}{|l|}{ Up-regulated } \\
\hline 243378_at & BE673747 & cDNA clone IMAGE: 3278205 & $5.2 \uparrow$ \\
\hline 242255_at & R49102 & KIAA0982 protein & $4.0 \uparrow$ \\
\hline 242161_at & AI458049 & cDNA clone IMAGE:2146521 (STK17A) & $4.0 \uparrow$ \\
\hline 236705_at & AA017245 & Hypothetical protein MGC42090 & $3.4 \uparrow$ \\
\hline
\end{tabular}

as GRO- $\alpha$ (CXCL1/MGSA), and IL-8 (CXCL8) decreased 3-fold. Moreover, three chemokines, MCP-3 (CCL7), GRO- 3 (CXCL2) and GRO- $\gamma$ (CXCL3), showed a more than 2-fold down-regulation upon CD43 overexpression (Table I). Elevated CD43 levels reduced the expression of N-myristoyltransferase 2 (NMT2), ataxin 2-related protein (A2LP), protocadherin 7 (PCDH7), nuclear matrix protein matrin 3 (MATR3), DNAJC8 (DnaJ, a Hsp40 homolog, subfamily C, member 8) and 14-3-3 epsilon. The latter has been previously shown to be repressed by CD43 (24).

To confirm some of the gene array results, the mRNA expression levels of chemokines GRO- $\alpha$, IL-8, and MCP-1 were further studied by semi-quantitative RT-PCR. The results confirmed decreased expression of GRO- $\alpha$, MCP-1 and IL-8 upon CD43 overexpression for 44-h tet-on (Fig. 2A). To exclude clonal effects, GRO- $\alpha$, MCP-1 and IL- 8 mRNA levels were also studied in the SW480/CD43 pool of transfectants.

CD43 suppresses the production of proinflammatory chemokines. To further investigate if CD43 inhibits the production of chemokines, the levels of GRO- $\alpha$, MCP- 1 and IL- 8 were analyzed in the cell culture medium of SW480/CD43 and SW480/lacZ cells by ELISA. MCP-1 secretion was reduced 3.6-fold whereas GRO- $\alpha$ and IL-8 secretion were reduced 3-fold after 48-h tet-on in the SW480/CD43 cells, showing a good correlation with the cDNA array results. In the control cells, no major changes in the levels of secreted chemokines were observed (Fig. 2B). Overexpression of CD43 reduced the transcription of IL-8 in SW480/CD43 cells (Fig. 2A), but both the mRNA and protein levels of IL-8, in contrast to GRO- $\alpha$ and MCP-1, were higher in non-induced SW480/CD43 cells as compared to SW480/lacZ cells. This suggests that the elevated CD43 expression in the non-induced SW480/CD43 cells (Fig. 1D) may cause increased IL-8 levels. In T cells, CD43 has been shown to enhance IL-8 production (25). The inhibition of chemokine production correlated with the reduced mRNA levels indicating that $\mathrm{CD} 43$ can regulate the transcription of proinflammatory molecules.

CD43 interferes with the transcriptional activity of $N F-\kappa B$. One of the main modulators of genes involved in the control of immune and inflammatory responses, including chemokines and cytokines, is the nuclear factor $\kappa \mathrm{B}(\mathrm{NF}-\kappa \mathrm{B})$ family of transcription factors. Due to the fact that elevation of CD43 levels decreased the expression of several NF- $\mathrm{KB}$ target genes, such as GRO- $\alpha$, MCP-1 and protocadherin 7 , we investigated 


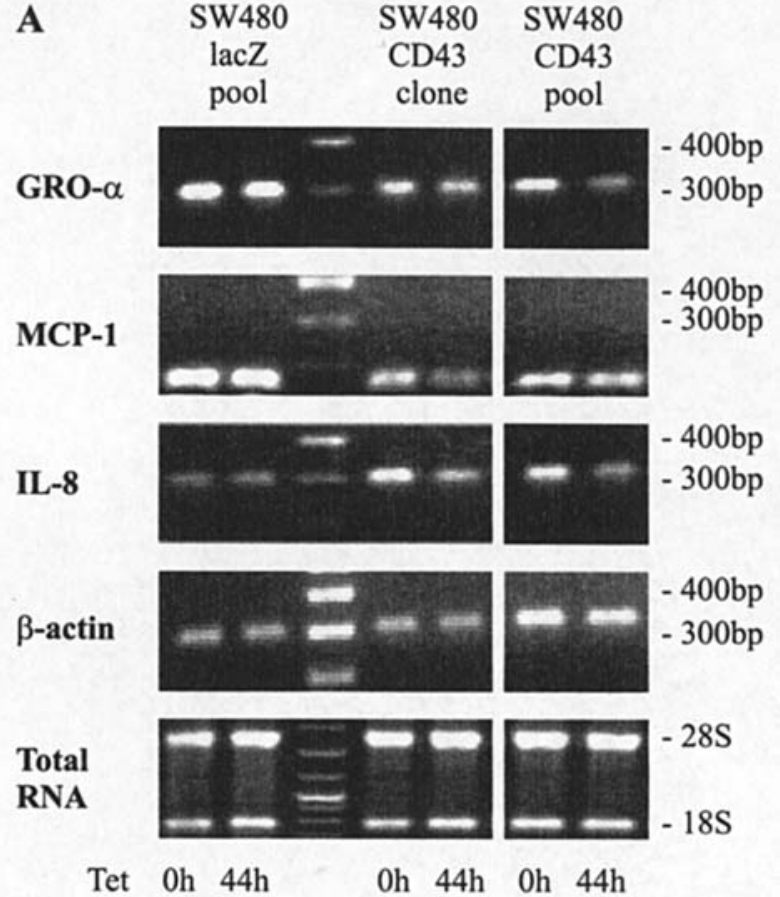

B
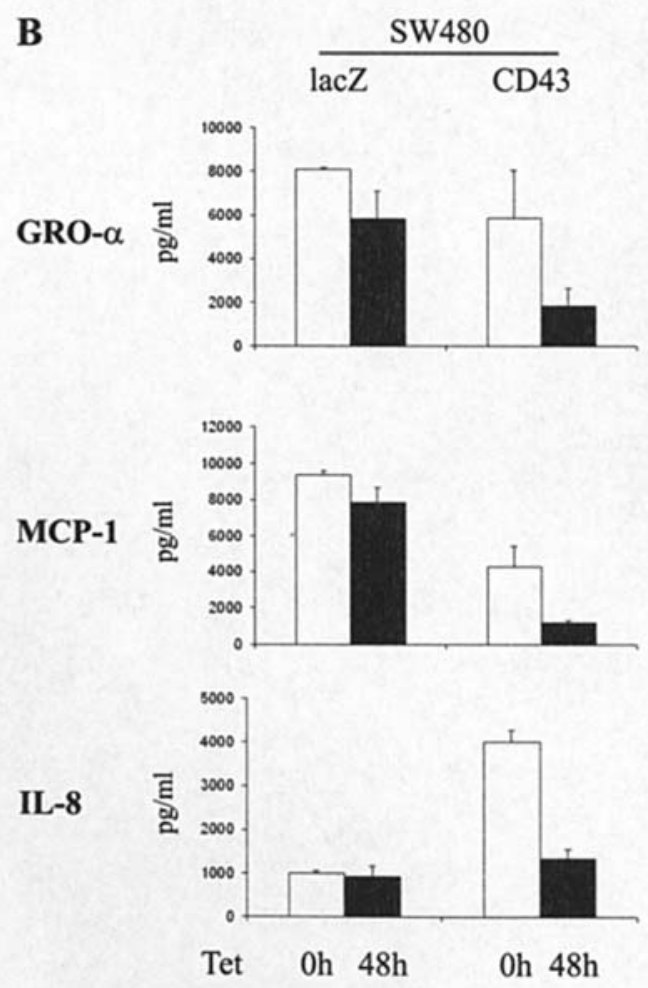

Figure 2. Overexpression of CD43 lowers mRNA expression and protein secretion of the chemokines, GRO- $\alpha$, MCP-1 and IL- 8 . (A) Total RNA was extracted from the 44-h tet-on SW480/lacZ and SW480/CD43 pool of cells and from the SW480/CD43 clone, reverse transcribed and subjected to RT-PCR by using primers specific for $\beta$-actin, GRO- $\alpha$, MCP-1 and IL- 8 . Sub-saturating levels of RT-PCR products (cycle 25) were compared using $2 \%$ agarose gel electrophoresis. Total RNA $(1 \mu \mathrm{g})$ was also analyzed revealing equal amounts. (B) The levels of chemokines GRO- $\alpha$, MCP- 1 and IL-8 were determined after 48-h tet-on in the SW480/CD43 and SW480/lacZ cell culture medium by ELISA (pg/ml). The results represent the mean $\pm \mathrm{SD}$ of two independent experiments performed in duplicate.

whether the transcription factor, $\mathrm{NF}-\mathrm{\kappa B}$, could be one of the regulators of their expression in the studied cells. NF- $\mathrm{KB}$ target promoter activation upon CD43 overexpression was tested using a luciferase reporter. The SW480 cells were transiently transfected with NF-кB luciferase reporter plasmid and the relative luciferase activity of non-induced and 24-h tet-on cells was compared. The promoter activity was significantly reduced in the CD43 overexpressing cells compared to control cells (Fig. 3A). This suggests that the observed inhibition of chemokine transcription can be mediated by reduced transcriptional activity of NF-кB. However, in some experiments, it was noticed that the basal level of NF- $\mathrm{KB}$ luciferase activity was higher in SW480/CD43 cells than in SW480/lacZ cells (data not shown), indicating that low levels of CD43, probably due to promoter leakage, may increase NF-кB activity. This could explain the observed higher IL-8 secretion in the non-induced SW480/CD43 cells. Next, we tested the CD43-dependent inhibition of NF-kB in phorbol ester (PMA)-activated cells. PMA stimulation for $24 \mathrm{~h}$ increased the expression of the $\mathrm{NF}-\kappa \mathrm{B}$ promoter dependent reporter by approximately 2 -fold. In SW480/CD43 cells, CD43 overexpression significantly reduced $\mathrm{NF}-\kappa \mathrm{B}$ promoter activity whereas control cells did not show any alterations (Fig. 3A). As NF-kB is known to cooperate with other transcription factors, such as activating protein 1 (AP-1) and B-catenin, luciferase reporter assays were used to study the target promoter activity. Transfected and PMA-treated 24-h tet-on SW480/lacZ and SW480/CD43 cells did not show any significant changes of AP-1 (Fig. 3B) or $B$-catenin (data not shown) responsive transcriptional activity upon CD43 induction.

CD43 suppresses the nuclear localization and DNA binding activity of $N F-\kappa B$ p65. There are five known mammalian NF-кB family members: p65 (RelA), RelB, c-Rel, NF-кB1 (p50/p105) and NF-кB2 (p52/p100), which can form homoor heterodimers. In most cell types, the inactive $N F-\kappa B$ complex, commonly composed of p65 and p50 subunits, is located in the cytoplasm bound to their inhibitors, IкBs. Upon activation by different stimuli, IкB kinase complex (IKK) is activated, resulting in the phosphorylation of IкB, which targets IкB to proteolytic degradation. Removal of this inhibitory complex allows active NF- $\mathrm{kB}$ dimers to translocate to the nucleus, bind specific DNA motifs called $\kappa \mathrm{B}$ sites, and activate target gene transcription (26). The NF-кB pathway is regulated by many processes, including IKK activity, posttranslational modifications as well as nucleocytoplasmic shuttling of various components of the pathway.

At first we asked whether CD43 could interfere with p65 and p50 localization to the nucleus by subjecting separated nuclear and cytoplasmic fractions to Western blot analysis. In unstimulated SW480 cells, the majority of p65 and p50 were located in the cytoplasm, but with detectable amounts also in the nucleus. When the nuclear fractions were analyzed, 15-, 27and 51-h tet-on SW480/CD43 cells showed reduced amounts of p65, but SW480/lacZ cells did not (Fig. 3C). With longer CD43 induction times, a time-dependent gradual decrease of p65 in the nucleus was revealed, whereas the amount of nuclear p50 was not affected. As the total amount of p65, measured by FACS, remained the same at 48-h tet-on CD43 (Fig. 3D), it probably did not affect the turnover of $\mathrm{p} 65$.

To determine the DNA binding activity of the $\mathrm{NF}-\kappa \mathrm{B}$ family, an ELISA-like assay was used. It employs immobilized 
$\mathbf{A}$

NF-кB-luc

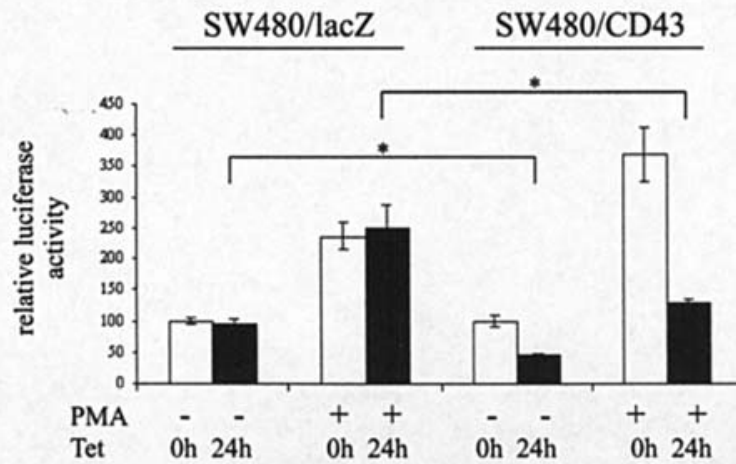

C

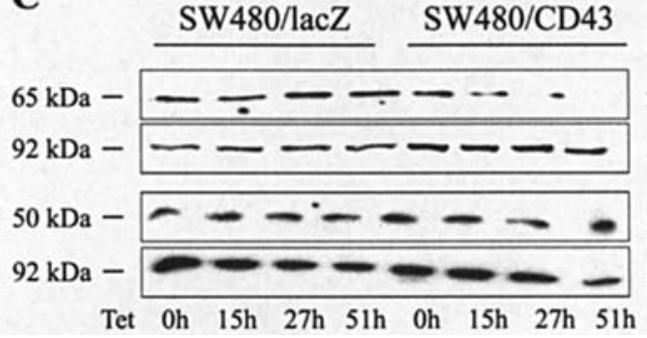

B

AP-1-luc

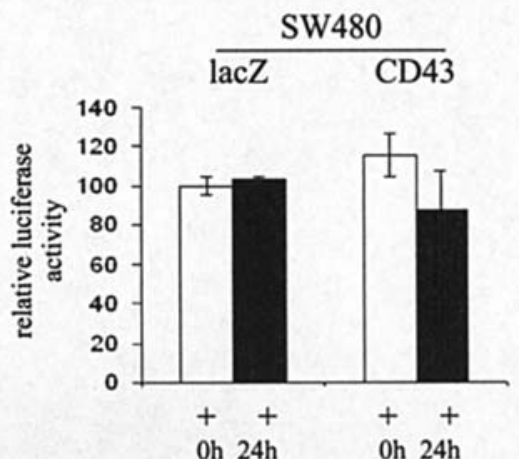

D

$$
\begin{aligned}
& \text { nucl. } p 65 \\
& \text { nucl. } \beta \text {-catenin } \\
& \text { nucl. } p 50 \\
& \text { nucl. } \beta \text {-catenin }
\end{aligned}
$$

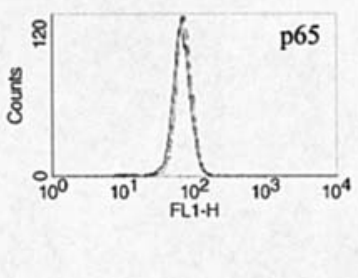

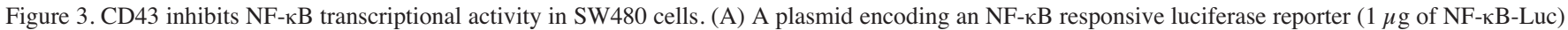
was transiently transfected into SW480/lacZ and SW480/CD43 cells, and the relative luciferase activities were measured $24 \mathrm{~h}$ after transfection. Simultaneously, the cells were 24-h tet-on, and stimulated with $100 \mathrm{ng} / \mathrm{ml}$ PMA. Relative luciferase activity is expressed as the percentage relative to tetracycline non-induced and non-PMA treated cells. All results were normalized to total protein determined with the BCA protein assay and presented as mean and standard error of the mean of two independent experiments performed in triplicate ( ${ }^{*} \mathrm{p}<0.05$, t-test). (B) AP-1-responsive promoter activity was determined by luciferase reporter assay in $100 \mathrm{ng} / \mathrm{ml}$ PMA-stimulated SW480/lacZ and SW480/CD43 cells. The cells were 24-h tet-on induced, transfected with $1 \mu \mathrm{g}$ AP-1-luc reporter plasmid and stimulated with $100 \mathrm{ng} / \mathrm{ml}$ PMA and $24 \mathrm{~h}$ later followed by the analysis of relative luciferase activity. (C) CD43 suppresses nuclear translocation of NF-кB p65. The cytoplasmic and nuclear extracts were separated, and the nuclear (nucl.) fraction analyzed by Western blotting after normalization of the total protein with the BCA protein assay. Western blot analysis of p65, p50 and ß-catenin in the nuclear fraction of 15 -, 27 and 51-h tet-on SW480/lacZ and SW480/CD43 cells showed reduced amounts of p65 in the nucleus upon CD43 overexpression, whereas nuclear p50 and ß-catenin levels were unaffected. (D) FACS analysis of NF- $\mathrm{B}$ p65 in permeabilised 48-h tet-on SW480/CD43 cells.

dsDNA corresponding to $\kappa \mathrm{B}$ sites to capture NF- $\kappa \mathrm{B}$ complexes and specific antibodies to detect bound transcription factors. The nuclear extracts of 24-h tet-on SW480/CD43 cells showed reduced p65 DNA binding compared to control cells (Fig. 4A), correlating with reduced amounts of $\mathrm{p} 65$ in the nucleus. The DNA binding of the other NF- $\mathrm{KB}$ family members (RelB, c-Rel) were not affected or showed no DNA binding (p50, $\mathrm{p} 52$ ), but the p65 binding activity was reduced already at 16-h tet-on (Fig. 4B).

To confirm that transcription factor p65 is involved in the regulation of chemokine expression in our system, SW480/ lacZ cells were transfected with p65 siRNA and, as a control, non-silencing siRNA. The cells were lysed $70 \mathrm{~h}$ after transfection and the cell culture medium was analyzed by MCP-1 ELISA. The p65 silenced cells showed decreased secretion of MCP-1 compared to the control cells, suggesting that MCP-1 expression is dependent on p65 in SW480 cells (Fig. 4C).

In order to confirm the inhibition of NF- $\mathrm{KB}$ by CD43 in different cell lines, NF- $\mathrm{KB}$ target promoter activation was also studied in MCF7 cells. Similarly to SW480/CD43 cells, 24-h tet-on MCF7/CD43 cells showed a significant reduction in basal NF- $\mathrm{KB}$ promoter activity as well as after 24-h PMA stimulation (Fig. 5A). Moreover, CD43 overexpression also decreased the nuclear p65 in MCF7 cells (Fig. 5B), showing that the effect was not restricted to colon cancer cells.

To study whether CD43 could interfere with constitutive nucleocytoplasmic shuttling of p65, we treated 24-h tet-on SW480/CD43 and MCF7/CD43 cells with leptomycin B (LMB), a selective inhibitor of chromosomal region maintenance-1 (CRM-1)-dependent nuclear export. Immunofluorescence studies of p65 in the presence of LMB for $24 \mathrm{~h}$ showed, as expected, that p65 localized almost exclusively in the nucleus. However, overexpression of CD43 in SW480 and MCF7 did not interrupt the nuclear accumulation of p65 after inhibition of nuclear export by LMB (data not shown). Recently, PPAR- $\gamma$ was shown to enhance the nuclear export of p65 (27). To address whether CD43 overexpression could enhance the nuclear export of $\mathrm{p} 65$ via PPAR- $\gamma$, the localization of PPAR- $\gamma$ was studied. However, CD43 overexpression did not cause any cytoplasmic relocalization of PPAR- $\gamma$ (Fig. 6A).

Finally, we examined whether CD43 interferes with $\mathrm{I} \kappa \mathrm{B} \alpha$ degradation after stimulation with $\mathrm{TNF} \alpha(15,30$ or $60 \mathrm{~min})$, which is a known potent proinflammatory cytokine and activator of $N F-\kappa B$. TNF $\alpha$-induced $N F-\kappa B$ activation is 
A

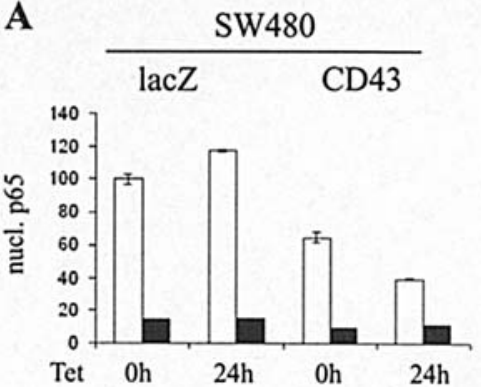

wt NF- B oligo

competitor oligo
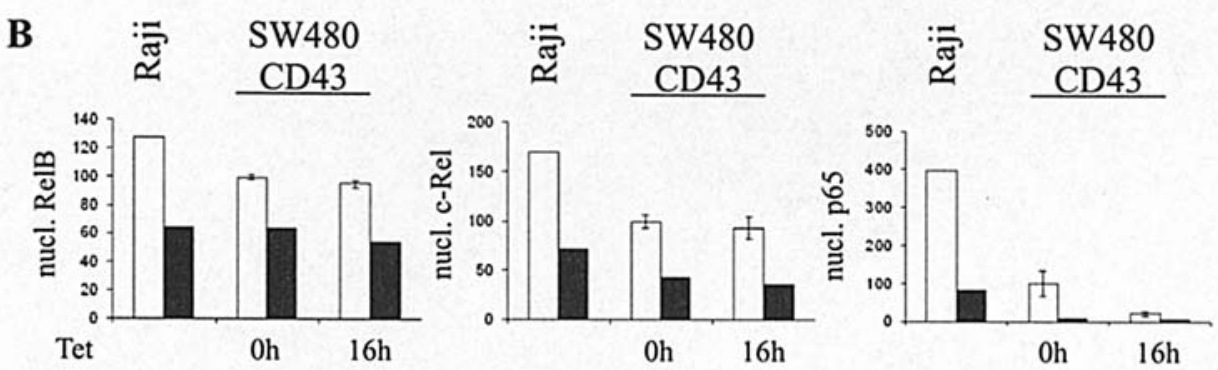

C
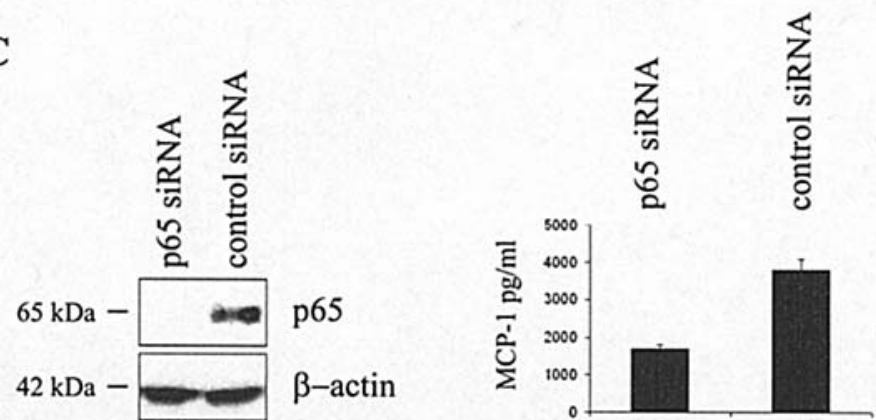

Figure 4. CD43 inhibits DNA binding of NF-кB p65. Nuclear lysates of SW480/lacZ and SW480/CD43 cells were prepared and NF-кB DNA binding activities determined by an ELISA-based assay. Wells with immobilized wild-type (wt) $\kappa \mathrm{B}$ element-containing DNA oligonucleotides and with $250 \mathrm{ng}$ of wt $\kappa \mathrm{B}$ elementcontaining the appropriate oligonucleotide in the solution (competitor) are shown. (A) p65 DNA binding activity of 24-h tet-on SW480/lacZ and SW480/CD43 cells. Results are presented as percentage of the means of absorbance (OD $650 \mathrm{~nm} \pm \mathrm{SD}$ of duplicate wells in one out of three representative experiments) relative to non-induced SW480/lacZ cells. (B) RelB, c-Rel and p65 DNA binding activities in nuclear lysates of 16-h tet-on SW480/CD43 cells. Cellular extract from Raji cells was used as a positive control. (C) p65 RNAi reduces MCP-1 production in the SW480 cells. SW480/lacZ cells were analyzed by Western blotting $70 \mathrm{~h}$ after transient transfection with p65 and control siRNA. The media were analyzed for MCP-1 by ELISA (pg/ml).

characterized by IKK-mediated IкB $\alpha$ phosphorylation and degradation (26). In 30-min TNF $\alpha$-treated cells, increased nuclear translocation of p65 compared to non-stimulated cells was observed (data not shown). Upon CD43 expression 24-h tet-on, SW480/CD43 cells again showed less p65 in the nucleus (Fig. 6B). TNF $\alpha$ treatment for 30 min caused complete IкB $\alpha$ degradation in SW480/lacZ cells whereas SW480/CD43 cells showed slower degradation of IкB $\alpha$ (Fig. 6C).

\section{Discussion}

A high expression of the leukocyte-associated antigen, CD43, has been found in human colorectal adenomas (4). The prevalence of CD43 expression in early stages of colon adenomas, not in normal colon, and variable expression in advanced colon carcinoma suggests a role during early colon tumor development. To study the potential functions of CD43 in cancer cells, a tetracycline inducible overexpression of CD43 in adenocarcinoma cell lines with low endogenous expression was established. In the studied colon adenocarcinoma cell line, SW480, overexpression of CD43 suppressed the transcription factor p65 activity and down-regulated the expression of pro-inflammatory genes, indicating that CD43 may play a negative role in the regulation of immune responses.

CD43 is an immunoregulatory molecule involved in seemingly contradictory functions as it can regulate $\mathrm{T}$ cell adhesion, homing, and activation both positively and negatively. The extracellular domain of CD43 can be differently glycosylated, directly affecting the immune function (28). However, the intracellular domain of CD43 is also important for immune regulation as it is involved in signal transduction. Ligation of CD43 with mAb causes PKC activation and triggers the MAP kinase pathway recruiting AP-1, NF- $\mathrm{BB}$ and NF-AT transcription factors (29). In contrast, ligation of CD43 with a mAb against another glycoform repressed the nuclear localization of NF- $\kappa \mathrm{B}$ (30). It is thus likely that different CD43 glycoforms have different effects on signal transduction.

In the present study, we show that CD43 overexpression in cancer cells inhibits NF- $\kappa \mathrm{B}$ activation, probably by reducing the DNA binding activity of transcription factor p65 and not 
A
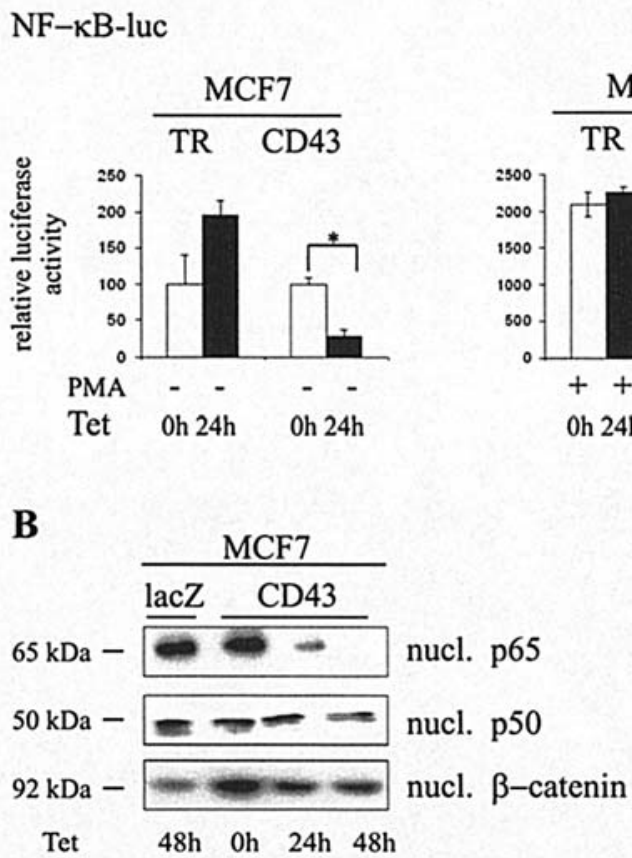

Figure 5. CD43 inhibits NF- $\mathrm{kB}$ in MCF7 cells. (A) NF- $\mathrm{kB}$ responsive luciferase reporter plasmid was transfected into MCF7/lacZ and MCF7/CD43 cells and the relative luciferase activities were measured $24 \mathrm{~h}$ after transfection. The cells were induced as indicated with tetracycline and stimulated with $100 \mathrm{ng} / \mathrm{ml}$ PMA for $24 \mathrm{~h}$. The results are normalized to total protein determined with the BCA protein assay and presented as mean and standard error of the mean of two independent experiments performed in duplicate ( $\mathrm{p}<0.05$, t-test). (B) Western blot analysis of nuclear p65, p50 and B-catenin in 24- and 48-h tet-on MCF7/CD43 cells showing decreased amount of nuclear $\mathrm{p} 65$.

p50, which may be dependent on slower $\mathrm{I} \kappa \mathrm{B} \alpha$ degradation. The inhibition of p65 activity was linked to the lower secretion of the proinflammatory chemokine, MCP-1, in SW480 cells. The promoters of MCP-1, and IL-8 genes are known to be dependent on transcription factor p65/p65 and p65/p50 dimer complexes for activation (31). This suggests that CD43 may regulate chemokine expression via suppression of p65 DNA binding activity. It has also been reported that expression of IL-8 and MCP-1 is dependent on B-catenin $(32,33)$. As we have previously shown that the cytoplasmic tail of CD43 can localize to the nucleus and interact with $B$-catenin when expressed as a stabilized protein by fusion with GFP, the present results might depend on $\beta$-catenin as well as NF-кB (19). However, overexpression of full-length CD43 in the present cell lines did not show any nuclear localization suggesting that the observed effects of CD43 overexpression are more likely due to the cytoplasmic and membrane localized interference of $\mathrm{NF}-\kappa \mathrm{B}$ signaling. We did not observe any transactivation effect of CD43 on a $\beta$-catenin responsive promotor reporter (data not shown), but it cannot be excluded that the observed effects might be linked to $\beta$-catenin. Importantly, ß-catenin was shown to form a complex with $\mathrm{NF}-\kappa \mathrm{B}$, reduce its DNA binding, and repress target gene expression in human colon and breast cancer cells (34).

As CD43 overexpression caused inhibition of NF-кB, we speculate that tumor cells expressing CD43 may suppress immune responses via inhibition of chemokine expression. The
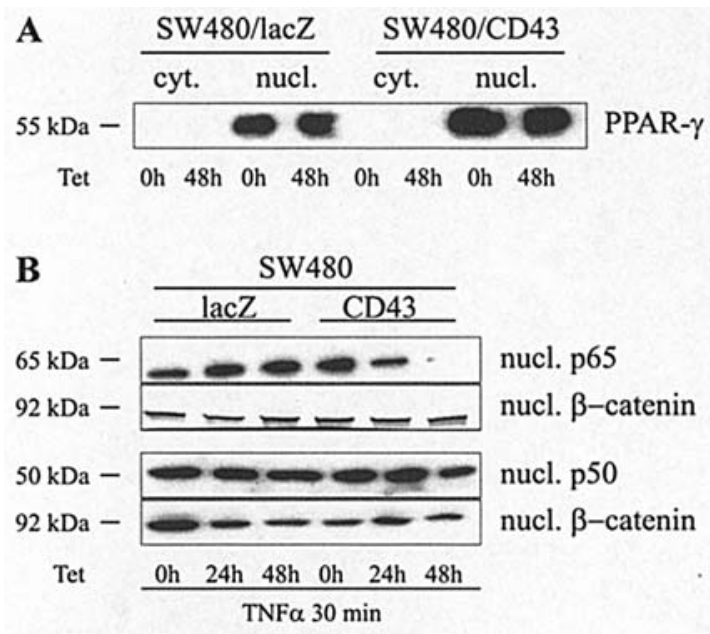

C

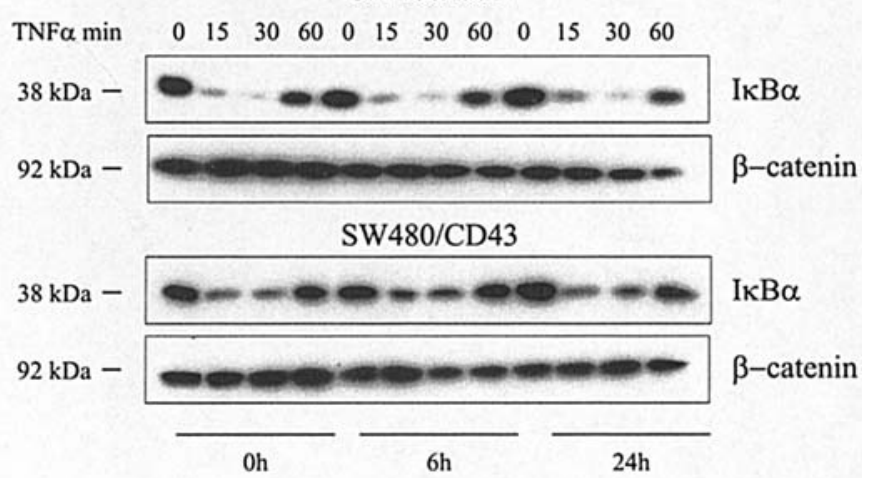

Figure 6. (A) Western blot analysis of PPAR- $\gamma$ in the nuclear and cytoplasmic fraction of 48-h tet-on SW480 cells. CD43 did not induce translocation of PPAR- $\gamma$ from the nucleus to the cytoplasm. (B) SW480/lacZ and SW480/CD43 cells were treated with $10 \mathrm{ng} / \mathrm{ml} \mathrm{TNF} \alpha$ for $30 \mathrm{~min}$, and the nuclear fractions were analyzed by Western blotting using p65, p50 and B-catenin antibodies. CD43 overexpressing cells showed smaller amounts of nuclear p65 whereas nuclear p50 and ß-catenin levels were unaffected upon $\mathrm{TNF} \alpha$ treatment. (C) Kinetics of TNF $\alpha$ induced $\mathrm{I} \kappa \mathrm{B} \alpha$ degradation in SW480/ lacZ and SW480/CD43 cells. The 0-, 6- and 24-h tet-on SW480/lacZ and SW480/CD43 cells were treated with $\mathrm{TNF} \alpha$ for 15,30 and $60 \mathrm{~min}$, and Western blot analysis was performed with $\mathrm{I} \kappa \mathrm{B} \alpha$, and $\beta$-catenin antibodies.

biological significance of chemokines in the tumor microenvironment is complex. Chemokines can influence the extent of infiltration and phenotype of the immune cells entering the tumors, affect angiogenesis and tumor cell growth, survival and migration. Some of the chemokines have a dual and biphasic effect on tumor growth. One such example is MCP-1, an important determinant of macrophage infiltration into tumors. Low levels of MCP-1 secreted by melanoma cells gave modest monocyte infiltration, whereas high levels invoked massive macrophage infiltration and tumor destruction (35). Thus, high expression levels of CD43 that can suppress chemokine secretion may represent a mechanism to lower the infiltration of immune cells into a developing tumor. In later stages of colon carcinogenesis, chemokines might positively contribute to tumor growth. In fact, CD43 expression is significantly reduced in later stages of colon carcinoma development (4).

It is commonly believed that NF- $\mathrm{KB}$ activation contributes to tumor progression. Increased activity of NF- $\mathrm{BB}$ is detected in many cancer cell lines derived either from hematopoetic or solid tumors, as well as in tumor tissue of different origins. 
However, the role of the NF-кB pathway in oncogenesis tends to be cellular context dependent as several recent observations also suggest NF- $\mathrm{KB}$ contribution to pathways inhibiting cancer development. Inhibition of NF- $\mathrm{KB}$ in skin cells was linked to the development of squamous cell carcinoma $(36,37)$. Furthermore, depletion of NF- $\mathrm{KB}$ p65 resulted in a malignant phenotype of embryonic fibroblasts (38) and overexpression of NF-кB p65 in MCF7 cells reduced tumorigenicity in nude mice (39). In colon cancer cell lines, expression of the oncogenes, B-catenin and Ras, was shown to decrease the NF- $\mathrm{kB}$ p65 activity $(34,40)$. Thus, in certain situations, CD43 may contribute to oncogenesis by inhibiting NF-kB p65. Moreover, NF- $\mathrm{BB}$ activity is modulated by the tumor suppressors, p53 and ARF, and it is proposed that NF- $\mathrm{\kappa B}$ might be tumor suppressing rather than tumor promoting in early stages of cancer (41). Importantly, CD43 causes activation of p53 via the tumor suppressor protein, ARF (20). When these tumor suppressor proteins were active, NF- $\mathrm{kB}$ p 65 was demonstrated to repress rather than activate anti-apoptotic gene expression (42). Thus, CD43 expression in tumor cells may have a complex contribution to cell fate during tumor development. The phenotypic effects and biological significance of CD43 expression in early colon tumor development might be dependent on CD43 dosage as well as the status of tumor suppressor proteins.

In brief, overexpressed CD43 suppressed NF-кB p65 in the studied cancer cell lines. However, further experiments are necessary to explain more precisely how CD43 mediates this effect on NF-кB signaling, information that should help us to understand how CD43 could be involved in early colon tumor development.

\section{Acknowledgements}

The project was supported by the Swedish Cancer Foundation, IngaBritt and Arne Lundberg Foundation and the Swedish Institute. We are grateful to Christian X. Andersson and Julia Fernandez-Rodriguez for useful discussions.

\section{References}

1. Remold-O'Donnell E, Zimmerman C, Kenney D and Rosen FS: Expression on blood cells of sialophorin, the surface glycoprotein that is defective in Wiskott-Aldrich syndrome. Blood 70: 104-109, 1987

2. Fernandez-Rodriguez J, Andersson CX, Laos S, Baeckstrom D, Sikut A, Sikut R and Hansson GC: The leukocyte antigen CD43 is expressed in different cell lines of non-hematopoietic origin. Tumour Biol 23: 193-201, 2002.

3. Santamaria M, Lopez-Beltran A, Toro M, Pena J and Molina IJ: Specific monoclonal antibodies against leukocyte-restricted cell surface molecule CD43 react with nonhematopoietic tumor cells. Cancer Res 56: 3526-3529, 1996.

4. Sikut R, Nilsson O, Baeckstrom D and Hansson GC: Colon adenoma and cancer cells aberrantly express the leukocyteassociated sialoglycoprotein CD43. Biochem Biophys Res Commun 238: 612-616, 1997

5. Pimenidou A, Madden LA, Topping KP, Smith KA, Monson JR and Greenman J: Novel CD43 specific phage antibodies react with early stage colorectal tumours. Oncol Rep 11: 327-331, 2004.

6. Shelley CS, Remold-O'Donnell E, Davis AE, Bruns GA, Rosen FS, Carroll MC and Whitehead AS: Molecular characterization of sialophorin (CD43), the lymphocyte surface sialoglycoprotein defective in Wiskott-Aldrich syndrome. Proc Natl Acad Sci USA 86: 2819-2823, 1989.
7. Pallant A, Eskenazi A, Mattei MG, Fournier RE, Carlsson SR, Fukuda M and Frelinger JG: Characterization of cDNAs encoding human leukosialin and localization of the leukosialin gene to chromosome 16. Proc Natl Acad Sci USA 86: 1328-1332, 1989.

8. Ellies LG, Jones AT, Williams MJ and Ziltener HJ: Differential regulation of CD43 glycoforms on CD4+ and CD8+ T lymphocytes in graft-versus-host disease. Glycobiology 4: 885-893, 1994.

9. Sperling AI, Green JM, Mosley RL, Smith PL, Di Paolo RJ, Klein JR, Bluestone JA and Thompson CB: CD43 is a murine T cell costimulatory receptor that functions independently of CD28. J Exp Med 182: 139-146, 1995.

10. Cruz-Munoz ME, Salas-Vidal E, Salaiza-Suazo N, Becker I, Pedraza-Alva G and Rosenstein Y: The CD43 coreceptor molecule recruits the zeta-chain as part of its signaling pathway. J Immunol 171: 1901-1908, 2003.

11. Manjunath N, Correa M, Ardman M and Ardman B: Negative regulation of T-cell adhesion and activation by CD43. Nature 377: 535-538, 1995.

12. Onami T, Harrington LE, Williams MA, Galvan M, Larsen CP, Pearson TC, Manjunath N, Baum LG, Pearce BD and Ahmed R: Dynamic regulation of $\mathrm{T}$ cell immunity by CD43. J Immunol 168: 6022-6031, 2002.

13. Delon J, Kaibuchi K and Germain RN: Exclusion of CD43 from the immunological synapse is mediated by phosphorylationregulated relocation of the cytoskeletal adaptor moesin. Immunity 15: 691-701, 2001.

14. Ostberg JR, Barth RK and Frelinger JG: The Roman god Janus: a paradigm for the function of CD43. Immunol Today 19: 546-550, 1998.

15. Remold-O'Donnell E and Rosen FS: Sialophorin (CD43) and the Wiskott-Aldrich syndrome. Immunodefic Rev 2: 151-174, 1990.

16. Lefebvre JC, Giordanengo V, Limouse M, Doglio A, Cucchiarini M, Monpoux F, Mariani R and Peyron JF: Altered glycosylation of leukosialin, CD43, in HIV-1-infected cells of the CEM line. J Exp Med 180: 1609-1617, 1994.

17. Zhang K, Baeckstrom D, Brevinge $H$ and Hansson GC: Comparison of sialyl-Lewis a-carrying CD43 and MUC1 mucins secreted from a colon carcinoma cell line for E-selectin binding and inhibition of leukocyte adhesion. Tumour Biol 18: 175-187, 1997.

18. He YW and Bevan MJ: High level expression of CD43 inhibits $\mathrm{T}$ cell receptor/CD3-mediated apoptosis. J Exp Med 190: 1903-1908, 1999.

19. Andersson CX, Fernandez-Rodriguez J, Laos S, Sikut R, Sikut A, Baeckstrom D and Hansson GC: CD43 has a functional NLS, interacts with beta-catenin, and affects gene expression. Biochem Biophys Res Commun 316: 12-17, 2004.

20. Kadaja L, Laos S and Maimets T: Overexpression of leukocyte marker CD43 causes activation of the tumor suppressor proteins p53 and ARF. Oncogene 23: 2523-2530, 2004.

21. Remold-O'Donnell E, Kenney DM, Parkman R, Cairns L, Savage B and Rosen FS: Characterization of a human lymphocyte surface sialoglycoprotein that is defective in Wiskott-Aldrich syndrome. J Exp Med 159: 1705-1723, 1984.

22. Sikut R, Andersson CX, Sikut A, Fernandez-Rodriguez J, Karlsson NG and Hansson GC: Detection of CD43 (leukosialin) in colon adenoma and adenocarcinoma by novel monoclonal antibodies against its intracellular domain. Int J Cancer 82: $52-58,1999$.

23. Fukuda M and Carlsson SR: Leukosialin, a major sialoglycoprotein on human leukocytes as differentiation antigens. Med Biol 64: 335-343, 1986.

24. Cermak L, Simova S, Pintzas A, Horejsi V and Andera L: Molecular Mechanisms Involved in CD43-mediated apoptosis of TF-1 Cells. Roles of transcription Daxx expression and adhesion molecules. J Biol Chem 277: 7955-7961, 2002.

25. Mattioli I, Dittrich-Breiholts O, Kracht M, Livingstone M and Schmitz ML: A comparative analysis of T cell costimulation and CD43 activation reveals novel signaling pathways and target genes. Blood 104: 3302-3304, 2004.

26. Ghosh S and Karin M: Missing pieces in the NF-kappaB puzzle. Cell 109: S81-S96, 2002.

27. Kelly D, Campbell JI, King TP, Grant G, Jansson EA, Coutts AG, Pettersson S and Conway S: Commensal anaerobic gut bacteria attenuate inflammation by regulating nuclear-cytoplasmic shuttling of PPAR-gamma and RelA. Nat Immunol 5: 104-112, 2004.

28. Daniels MA, Hogquist KA and Jameson SC: Sweet ' $n$ ' sour: the impact of differential glycosylation on $\mathrm{T}$ cell responses. Nat Immunol 3: 903-910, 2002. 
29. Santana MA, Pedraza-Alva G, Olivares-Zavaleta N, MadridMarina V, Horejsi V, Burakoff SJ and Rosenstein Y: CD43mediated signals induce DNA-binding activity of AP-1, NF-AT and $\mathrm{NF}_{\kappa} \mathrm{B}$ transcription factors in human $\mathrm{T}$ lymphocytes. J Biol Chem 275: 31460-31468, 2000.

30. Brown TJ, Shuford WW, Wang WC, Nadler SG, Bailey TS, Marquardt $\mathrm{H}$ and Mittler RS: Characterization of a CD43/ leukosialin-mediated pathway for inducing apoptosis in human T-lymphoblastoid cells. J Biol Chem 271: 27686-27695, 1996.

31. Ritchie MH, Fillmore RA, Lausch RN and Oakes JE: A role for NF-kappa B binding motifs in the differential induction of chemokine gene expression in human corneal epithelial cells. Invest Ophthalmol Vis Sci 45: 2299-2305, 2004.

32. Levy L, Neuveut C, Renard CA, Charneau P, Branchereau S, Gauthier F, van Nhieu JT, Cherqui D, Petit-Bertron AF, Mathieu D and Buendia MA: Transcriptional activation of interleukin-8 by beta-catenin-Tcf4. J Biol Chem 277: 42386-42393, 2002.

33. Mestdagt M, Polette M, Buttice G, Noel A, Ueda A, Foidart JM and Gilles C: Transactivation of MCP-1/CCL2 by beta-catenin/ TCF-4 in human breast cancer cells. Int J Cancer 118: 135-142, 2005.

34. Deng J MS, Wang HY, Xia W, Wen Y, Zhou BP, Li Y, Lin SY and Hung MC: beta-catenin interacts with and inhibits NF-kappa $\mathrm{B}$ in human colon and breast cancer. Cancer Cell 2: 323-334, 2002.

35. Nesbit M, Schaider H, Miller TH and Herlyn M: Low-level monocyte chemoattractant protein-1 stimulation of monocytes leads to tumor formation in nontumorigenic melanoma cells. J Immunol 166: 6483-6490, 2001.
36. Dajee M, Lazarov M, Zhang JY, Cai T, Green CL, Russell AJ, Marinkovich MP, Tao S, Lin Q, Kubo Y and Khavari PA: NFkappaB blockade and oncogenic Ras trigger invasive human epidermal neoplasia. Nature 421: 639-643, 2003.

37. Van Hogerlinden M, Rozell BL, Ahrlund-Richter L and Toftgard R: Squamous cell carcinomas and increased apoptosis in skin with inhibited Rel/nuclear factor-kappaB signaling. Cancer Res 59: 3299-3303, 1999.

38. Gapuzan ME, Yufit PV and Gilmore TD: Immortalized embryonic mouse fibroblasts lacking the RelA subunit of transcription factor NF-kappaB have a malignantly transformed phenotype. Oncogene 21: 2484-2492, 2002.

39. Ricca A, Biroccio A, Trisciuoglio D, Cippitelli M, Zupi G and Del Bufalo D: relA over-expression reduces tumorigenicity and activates apoptosis in human cancer cells. Br J Cancer 85: 1914-1921, 2001.

40. Cadoret A, Bertrand F, Baron-Delage S, Levy P, Courtois G, Gespach C, Capeau J and Cherqui G: Down-regulation of NFkappaB activity and NF-kappaB p65 subunit expression by ras and polyoma middle $\mathrm{T}$ oncogenes in human colonic Caco-2 cells. Oncogene 14: 1589-1600, 1997.

41. Perkins ND: NF-kappaB: tumor promoter or suppressor? Trends Cell Biol 14: 64-69, 2004.

42. Campbell KJ, Rocha S and Perkins ND: Active repression of antiapoptotic gene expression by RelA(p65) NF-kappa B. Mol Cell 13: 853-865, 2004. 